\title{
LOS REGÍMENES DE TENENCIA INDIRECTOS EN LA AGRICULTURA ANDALUZA: EVOLUCIÓN Y ESTADO ACTUAL
}

\author{
Víctor O. Martín Martín \\ Departamento de Geografía \\ Universidad de La Laguna
}

\section{RESUMEN}

Se expone una síntesis bibliográfica (con trabajo de campo y entrevistas) para una interpretación teórica de las causas de la estabilidad del latifundio extensivo en el Sur de España. El artículo aporta una explicación de la génesis y evolución de los regímenes de tenencia indirectos de la tierra en la diversidad de los sistemas agrarios de Andalucía. Es decir, cómo se adapta la economía terrateniente a la nueva y singular realidad española surgida a partir de la reforma agraria liberal desde el punto de vista de la contratación de la mano de obra de sus predios en: a) la dehesa de Los Pedroches, b) la Sierra Morena, c) el regadío del Valle del Guadalquivir, d) los secanos de La Campiña y altiplanicies interiores y e) los olivares de las Subbéticas. Durante décadas y hasta los años sesenta del siglo XX estas agriculturas andaluzas evolucionaron manteniendo el régimen contemporáneo de la economía terrateniente como producto de la combinación del sistema de pagos en trabajo o precapitalista y del capitalista. En los años sesenta se produce la crisis y readaptación de todos estos sistemas agrarios: sostendremos que desaparecen los regímenes de tenencia indirectos, pero se mantiene la gran propiedad latifundista mediante el control del poder político.

Palabras clave: relaciones de producción, sistema agrario, gran propiedad, poder político, Andalucía.

\begin{abstract}
The pre-capitalist relations of production in the Andalusian agriculture: evolution and current situation

There is exposed a bibliographical synthesis (with fieldwork and interviews) to explain the reasons of the stability of the great property in the South of Spain. The article contributes an explanation of the genesis and evolution of the pre-capitalist relations of production in the agrarian systems of Andalusia: Pedroches, Sierra Morena, Valley of the Guadalquivir, Campiña and Subbéticas. In the sixties there takes place the crisis and readaptation of all these agrarian systems, eliminating the pre-capitalist relations, but the great property becomes stable economically by means of the control of the political power.
\end{abstract}


Key-words: relations of production, agrarian system, great property, political power, Andalusia.

\section{La dehesa cordobesa de los pedroches}

En el norte de Córdoba, después de las elevaciones de la Sierra Morena que se asoman al valle del Guadalquivir, el batolito de los Pedroches presenta un paisaje agrario singular que anuncia ya Extremadura: la dehesa. El aprovechamiento agro-silvo-pastoril de la dehesa se organizó, desde el punto de vista de la economía política, como uno de los sistemas donde mayor predominio tuvieron las relaciones de producción precapitalistas entre los grandes propietarios ¿burgueses? que adquirieron las fincas en venta de la desamortización civil y los aparceros (pequeños campesinos y campesinos sin tierra, todavía más desposeídos como resultado de las ventas de tierras comunales). Esta particular forma de explotación de la dehesa predominará hasta la década de los sesenta del siglo XX, cuando entra en crisis y se produce una evolución que provoca la desaparición de forma paulatina de las relaciones precapitalistas del campo.

Según Valle (1985: 265-270), el proceso se inicia en el último cuarto del siglo XIX, pues las tierras que se pusieron en cultivo tras la desamortización civil ofrecieron la particularidad de no ser «desmontadas» por sus propietarios, lo cual se explica por su condición de grandes terratenientes, por el tamaño considerable de la mayoría de las fincas adquiridas y por la posibilidad económica que tenían aquellos de emplear mano de obra ajena. Estos desmontados se realizaron entre 1875 y 1930, teniendo su momento de mayor auge hacia 1900. Como señala Valle, los protagonistas fueron jornaleros y pelantrines de la comarca, que habían quedado desahuciados tras la privatización de los terrazgos comunales, y «materos» venidos expresamente de las provincias de Almería y Granada (conocidos con el nombre de mangurrinos) y de Cuenca y Guadalajara (serranos), es decir campesinos muy pobres de las montañas Béticas y de la montaña media de la Meseta.

Los yunteros, pelantrines y pegujaleros se ocuparon de los desmontados mediante convenios establecidos con los propietarios de la tierra, definiéndose un sistema de relaciones de producción tan autárquico como primitivo —en palabras de Valle-, consistente en el sincretismo entre cesión temporal de la tierra y aparcería. La finca a desmontar, o mejor a «descuajar», porque se trataba de eliminar de cuajo la vegetación para impedir su reproducción, se dividía en tantas partes como años de intermisión se estimaba que había de dejar entre cosecha y cosecha, y cada año se iba desmontando una de ellas. El dueño convenía con distintas personas la labor a realizar, señalándose suertes de tamaño proporcional a su fuerza de trabajo.

En ocasiones se asociaban dos personas, aportando cada una un asno con el que componían una yunta. Entre ambos llegaban a desmontar al cabo del año de cuatro a seis fanegas de tierra. En compensación al trabajo realizado obtenían del propietario la cesión de la suerte desmontada por un periodo de cuatro años. A esta superficie obtenían otras tantas cosechas que, en el mejor de los casos, solían ser la primera de garbanzos, la segunda de trigo, la tercera de garbanzos y la cuarta, nuevamente de trigo.

Pero el usufructo de la tierra desmontada, continua explicando Valle, no era gratuito, sino que habían de satisfacer y poner en casa del propietario una renta en especie que se reguló, según cultivo, en una cuartilla de garbanzos, media fanega de trigo o una de cebada por fanega de tierra sembrada.

Pese a que la remuneración del trabajo era inexistente y que sobre las cosechas pesaban los eventos climáticos, los desmontadores se sentían satisfechos porque podían cultivar 
unas tierras que se «empanaban» con muy poca semilla y proporcionaban rendimientos aceptables. Cosa diferente fue cuando en la década de 1920 comenzaron a escasear los desmontados y a disminuir los rendimientos.

Valle escribe que el propietario obtenía beneficios de la tierra sin necesidad de remunerar la mano de obra; por otra parte, para éste la aparcería, al constituir un sistema de riesgo compartido, le resultaba muy flexible, pues de otra manera hubiera tenido que satisfacer anualmente y con carácter fijo un número de jornales que por las eventualidades agroclimáticas podían representar en años malos un montante superior al valor de la cosecha recogida. Nosotros preguntaríamos y ¿cuándo esas eventualidades agroclimáticas llegaban, cubría sus necesidades el aparcero?

La aparcería, igualmente, resolvía al propietario el problema de la contratación temporal de la mano de obra, evitaba la inversión en aperos de labranza y otros medios de producción y limitaba la gestión empresarial a enviar a la era un medidor que tasara el grano obtenido y calculara la cantidad que correspondía al propietario y al aparcero.

Los contratos de aparcería se hacían verbalmente y por tiempo indefinido. La renta que se fijaba a favor del propietario oscilaba en torno al 35 ó $40 \%$; en los ruedos y en las fincas de mejor suelo se podía llegar hasta el 45 y, ocasionalmente, al $50 \%$; en cambio en las tierras de calidad inferior no sobrepasaba el $33 \%$.

Pero se debe tener en cuenta que las aparcerías afectaban solamente al cultivo, pues el aprovechamiento ganadero de los pastos, el arbolado y sus frutos quedaban a disposición del propietario, quien contrataba en este caso a los antiguos pegujaleros que no habían accedido a propiedad alguna, y que serán empleados ahora como pastores, vaqueros y porqueros. Con ello, los porcentajes anteriores se elevarían a favor del propietario si seguimos hablando de aparcería, si no habría que hablar de trabajo gratuito. Para nuestra hipótesis de trabajo no importa demasiado: ambos términos expresan relaciones de producción precapitalistas.

En ocasiones se estableció aparcería ganadera, pero esta estuvo más bien limitada al ganado caprino. En las restantes especies no prosperó porque la persona idónea para hacerse cargo de ella era el aparcero de labor y, por la escasez estival de pastos, había que sacar los rebaños a los agostaderos de la Campiña. Como ello coincidía con las faenas de trilla y saca, el aparcero se veía imposibilitado para conducir y apacentar el ganado. En su defecto tenía que contratar pastores cuya retribución era claramente precapitalista: una combinación entre metálico, especie y el hato de ganado que el propietario autorizaba (Cábanas, 1967: 216-217):

«Los ganaderos [de ovejas] viven en las dehesas con sus familiares, en chozas de forma cónica, constituidos por ellos mismos con un armazón de palo, vigas y horcones, sobre el que se coloca monte bajo, juncos, paja brava y otro material semejante...

Los ganaderos perciben por su trabajo una remuneración en metálico y en especie, y están autorizados para tener un número variable de cabezas de ganado de su propiedad. La cantidad en metálico suele ser en toda la comarca de 50 pesetas mensuales; las especies que constituyen el «hato»o «dádiva» son 12 fanegas de trigo, 24 litros de aceite, una fanega de garbanzos, tocino y algunos otros víveres más por año... La piara propia que se le autoriza tener se llama «excusa»o «libra»y consiste en 25 ó 30 al mayoral y 20 ó 25 al zagal.»

El sistema terrateniente en la dehesa estuvo funcionando en plenitud y sin variaciones apreciables hasta mediados de la década de los sesenta del pasado siglo, momentos en los que aparecen una serie de circunstancias que lo hicieron inviable. La primera de ellas 
y principal fue el éxodo poblacional, que le restó su tradicional aliado: la mano de obra abundante y barata en la que se basaban unos sistemas ganaderos tan extensivos; la segunda, la repoblación; la tercera su no adaptación a los mercados (Valle, 1985: 416; Valle, 1995: 243-246).

La emigración de los aparceros conllevó el resquebrajamiento de los regímenes de tenencia tradicionales y afectó de modo muy directo a la propia estructura agraria, debido a que la misma no supuso solamente la pérdida de un elemento clave en las explotaciones agrarias medianas y grandes, sino que con el aparcero emigró toda su familia, dentro de la cual solían existir dos o tres hijos varones que además del trabajo que realizaban para la familia solían emplearse temporalmente en otros menesteres agrícolas o ganaderos como mano de obra asalariada. Su emigración, pues, ocasionó a muchas explotaciones el doble perjuicio de quedar privadas de su aliado más rentable (el régimen de aparcería) y de tener que contratar la mano de obra en base a la demanda del empresario y no sobre la oferta de los jornaleros y pequeños propietarios (Valle, 1985: 433).

La respuesta a la crisis de los años sesenta del modelo de la dehesa supuso diversas modificaciones en las formas de explotación por parte de los grandes propietarios. Significativas son al respecto las palabras de uno de los iniciadores del sistema cooperativo en la comarca:

«Los grandes propietarios han ido para atrás, cuando se le iba la gente mecanizaban el cereal, después dedicaron las tierras a la caza y ahora viven de las ayudas de la CEE: trigo duro, ovejas... Algunos grandes tienen muchas ovejas, más de la capacidad de carga ganadera y es porque reciben ayudas por cabeza.» (ANTONIO VIGARA COPÉ, 28/2/03).

Mientras los grandes propietarios infrautilizan o sobreexplotan las grandes haciendas adehesadas, los aparceros que no emigraron se han transformado en ganaderos minifundistas. Mientras los grandes propietarios no manejan correctamente el sistema de la dehesa, los pequeños ganaderos privados de propiedad y rodeados de grandes latifundios se ven obligados a instaurar unas explotaciones ganaderas cuyos insumos provienen en su mayoría del exterior. Y es que el régimen de propiedad sigue marcando la evolución económica de la comarca. Valle lo describe perfectamente cuando señala que al objeto de atender a la producción láctea, el protagonismo ha corrido a cargo de la raza Frisona, la cual se mantiene en su estado de pureza originario a fin de aprovechar al máximo sus cualidades productivas. Se trata de una raza cuyas exigencias alimenticias de forrajes la hacen incompatible con el sistema de dehesa, de ahí que no haya podido integrarse en él. En consecuencia, ha originado una cabaña alóctona cuyos efectivos rondan las treinta mil cabezas y que se mantiene yuxtapuesta a las restantes especies ganaderas.

Su desarrollo, continua el autor referido, ha propiciado el surgimiento de una ganadería que responde a una estructura de propiedad minifundista y fundamentada en las escasas exigencias territoriales del sistema de granjería en el que se desenvuelve, aunque tampoco es ajena a las grandes explotaciones, donde se mantiene estabulada e independiente del resto del ganado. La conclusión a la que llega Valle es la que sigue (1995: 255):

«Si bien es cierto que la presencia de esta cabaña ha contribuido a resolver en Los Pedroches el problema social de las explotaciones más exiguas y de las sin tierra y al mismo tiempo, a aliviar el problema económico de las de mayor tamaño, su desadaptación ecológica, su elevado consumo en pienso, la situación excedentaria de la producción láctea, etc., constituyen ejemplos elocuentes de 
los desequilibrios y dependencias del modelo ganadero español y de sobre imposición paisajística al entorno agropecuario de la comarca.»

Antonio Vigara, partícipe de la nueva estrategia de estos pequeños propietarios, nos afirma la importancia actual de la misma:

«El sistema cooperativo mueve la economía de Los Pedroches. COVAP (Cooperativa del Valle de Los Pedroches) ya produce el $60 \%$ de la leche en Andalucía. Y está creciendo en otras producciones e instalaciones.» (ANTONIO VIGARA COPÉ, 28/2/03)

Imaginemos de lo que serían capaces estos pequeños ganaderos si tuvieran en sus manos las miles y miles de hectáreas pertenecientes a los grandes latifundios adehesados de la comarca.

\section{La Sierra Morena}

La ganadería extensiva practicada en bosques de encinas y alcornoques y en el monte bajo de la Sierra Morena fue similar a la dehesa hasta los años sesenta (salvo quizá en el menor peso de las tierras de labor en la sierra). Sin embargo, la evolución seguida a partir de esa década ha sido diferente entre uno y otro sistema agrario.

También aquí, una de las operaciones principales de la gestión corriente del agrosistema consistía en luchar contra el matorral, que vuelve constantemente y que representa un obstáculo al pastoreo y la montanera. El matorral de plantas cistáceas, madroños, brezos, ese matorral de vegetación espontánea que se encuentra en todas las sierras andaluzas, impide que crezca la hierba y hace difícil el paso de los animales, que en tales condiciones ya no pueden coger ni la hierba ni las bellotas. Ello explica que, tanto en la sierra como en la dehesa, la producción esté relacionada con la lucha contra el matorral y que haya sido este elemento en el manejo del sistema agrario una de las claves sobre la que han basculado los contratos precapitalistas. La sola presencia de los animales en los pastos naturales en bosques o fuera de bosques no es suficiente para impedir que vuelva a crecer el matorral para mantener la productividad de sus tierras; el ganadero debe intervenir, practicando una «limpieza» periódica.

En su estudio de la Sierra de Huelva, Roux (1975: 216-219) señala ejemplos que testimonian concretamente los efectos de la concentración de la tierra en las relaciones sociales.

El primero concierne al grupo social de los pegujaleros, campesinos sin tierras (o pequeños minifundistas) que cultivaban periódicamente las tierras de los grandes propietarios. En efecto, éstos preferían dejar las partes de la explotación invadidas por el matorral a los que no tenían tierras para que cultivasen los cereales necesarios para su propia subsistencia, más bien que efectuar ellos mismos esa limpieza. Teniendo en cuenta que la operación suponía mucho trabajo (limpiar, arrancando a mano los pequeños brotes de las plantas del matorral, y roturar) para conseguir rendimientos muy bajos (4 a $10 \mathrm{Qm} / \mathrm{Ha}$ ), es evidente que no tenían ningún interés en efectuarla ellos mismos. Después de un año o dos de cultivo de cereales, el pegujalero tenía que devolver el pegujal a su propietario, inmediatamente después de la cosecha. Entonces la tierra volvía a servir de pasto para el ganado del terrateniente durante varios años, hasta que de nuevo se encontrase invadida por el matorral y entonces otra vez se recurría al pegujalero. Generalmente el propietario se dirigía a un representante de los campesinos del pueblo o de las aldeas para informarle del lugar donde se encontraban las parcelas para cultivar. El representante transmitía la información a los pegujaleros, que 
se atribuían las tierras democráticamente. De este modo el ganadero mantenía sus tierras limpias completamente gratis e incluso recibía la décima parte de la cosecha como renta. El propio Roux señala que se puede ver en esas prácticas una supervivencia de las relaciones feudales. En cuanto al campesino sin tierra, tenía que aceptar ese arrendamiento precario e itinerante, único medio para él de proporcionarse los cereales que representaban entonces la base alimenticia de la gente del campo. Si esa operación le permitía subsistir, a él y a su familia, era a cambio de un trabajo considerable y, sobre todo, a cambio de un trabajo «perdido», ya que no podía permanecer en la tierra después de haberla mejorado. Pero, al fin y al cabo, el pegujalero no era el más desfavorecido dentro de la jerarquía social, ya que por lo menos podía cultivar la tierra, lo que significaba que tenía medios para hacerlo; es decir, poseía, al menos, una par de mulas (a esos campesinos sin tierra, pero propietarios de animales de tiro, también se les llamaban yunteros), capital que no estaba al alcance de todos, ni mucho menos, en los pueblos de Sierra Morena.

El segundo ejemplo que ilustra las relaciones sociales en la sociedad tradicional, es el trabajo que se efectuaba por eventuales para el mantenimiento de los encinares: la poda periódica de los árboles. La venta de las tierras municipales había dejado a los campesinos sin posibilidad de proporcionarse leña para las necesidades domésticas. Tenían prohibido el acceso a los bosques, por ser una propiedad privada, como no fueran obreros empleados por los propietarios o sus administradores. Ahora bien, el carbón de leña que esos bosques permitían fabricar representaba un producto indispensable para las familias de campesinos, que lo utilizaban para calentarse y para cocer los alimentos. La elaboración del carbón de leña era, además una verdadera profesión para muchos obreros agrícolas de las Sierras andaluzas.

Esas pervivencias precapitalistas, «capitalismo agrario arcaico» según Roux, que permitían superganancias considerables a los grandes propietarios, teniendo en cuenta el poco capital invertido, asegurando su dominación por la concentración de las tierras y los salarios bajos, obteniendo, gracias al hambre, unas ganancias superiores a las que hubieran tenido trabajando la tierra, no podía mantener su prosperidad más que a la condición de que España siguiera permaneciendo «inmóvil». Pero, a partir de los años sesenta, la economía del país se iba a transformar y el papel social y económico de los ganaderos importantes de la Sierra sería discutido.

M. Mazoyer, en el prólogo del libro de Roux (1975: 12-13), explicaba la crisis en que, allá por los años setenta, se encontraba el sistema terrateniente en la sierra andaluza. La Sierra Morena, por sus características, región poco fértil, no se ha beneficiado jamás de una renta diferencial primaria muy alta. A esta desventaja física se añade otra desventaja socio-histórica: la poca acumulación de capital y la pobreza del equipo de producción, las cuales engendran una baja productividad y una renta diferencial secundaria igualmente baja. A causa de dicha doble desventaja, escribía Mazoyer, las grandes empresas arcaicas que son los latifundios ganaderos de la Sierra Morena, tan sólo pueden sacar partido por su extensión y del hecho de beneficiarse de una fuerte mano de obra poco remunerada o de la posibilidad de dar salida a sus productos en unos precios poco competitivos. Estos latifundios no pueden luchar ni contra la competencia de las explotaciones familiares o capitalistas de las regiones desarrolladas en lo que a sus productos se refiere, ni contra la competencia de las grandes industrias en lo concerniente a mano de obra. El desarrollo industrial y la unificación de los mercados de productos y trabajo les pondrán en una situación desastrosa. Concluye este autor que los sistemas y las relaciones de producción no pueden reproducirse en esta zona poco fértil en el momento que la reserva de mano de obra «semi-cautiva» (nosotros diríamos semiservil), de la cual se beneficiaron durante largo tiempo, se encuentra «liberada» por el desarrollo de otros sectores. 
A partir de los años setenta el sistema agrario terrateniente de la dehesa, tanto en la Sierra Morena como en la Meseta, se va a caracterizar por la contradicción sub-explotación/sobreexplotación. Ni siquiera la revitalización de las producciones de la dehesa (trigo, oveja, cerdo...) producida como consecuencia de la integración de España en la Unión Europea va a permitir el funcionamiento adecuado de todas las potencialidades de las explotaciones adehesadas. La gran propiedad a) subexplota: abandona la actividad o dedica sus fincas a cotos de caza y al recreo o a la repoblación forestal; o b) sobreexplota: intentando conseguir las subvenciones comunitarias para el trigo o las primas por cabeza de ovino-caprino.

Roux (1975: 78) ya explicaba la subexplotación del sistema de dehesa a mediados de los años setenta. La ganadería porcina estaba experimentando una regresión indiscutible. Según el Censo Agrícola de 1962, se estimaba 0,66 cerdo por Ha. de encinar, para la totalidad de las explotaciones. En 1974, en las explotaciones encuestadas, tan sólo se estima el 0,35. La encuesta de Roux le revelaba que los ganaderos consideraban las potencialidades de sus explotaciones muy superiores a la producción de aquellos momentos.

La huida de los jornaleros y pequeños campesinos de las condiciones de explotación semiserviles en la dehesa se pone de manifiesto en el trabajo de Roux, cuando señala que durante los últimos años, esa operación para mantener limpias las tierras, a pesar de ser indispensables, ha sido muy descuidada por los ganaderos. Muchos empresarios, de un cierto modo, han «dimitido» ante las dificultades que tienen en encontrar a alguien que efectúe esa operación. Los que, a pesar de todo, limpian una parte de sus explotaciones, han abandonado por completo el cultivo de los cereales y únicamente practican el arranque mecánico, o, en ciertos casos todavía, manual (Roux, 1975: 176). Esta situación indicaba claramente que el matorral está ganado cada vez más terreno.

Entre las otras operaciones deseables para mantener la productividad de las explotaciones, la poda de las encinas y alcornoques es una de las que requieren más mano de obra. En las décadas centrales del siglo XX, los gastos relativos a ese trabajo se compensaban por la venta de los desperdicios de leña, lo que hacía esa operación una operación de coste nulo; sin embargo, cuando Roux escribe su obra, los empresarios tienen que emplear obreros para efectuar ese trabajo, la leña que servía para la fabricación del carbón ha perdido su valor comercial y los salarios han subido de manera considerable, por lo que esa operación es muy costosa. La mayor parte de los empresarios encuestados por Roux consideran que sus encinares y alcornocales están insuficientemente cuidados. Las causas de ese abandono son las mismas que las que explicaban la falta de limpieza del monte bajo.

Roux argumenta tres causas para explicar la desaparición previsible de lo que él denomina capitalismo latifundista o capitalismo arcaico. La primera (las otras dos serían la estructura agraria y los precios pagados a los ganaderos) radica en su propia naturaleza. En efecto, dice Roux, puesto que lo esencial del capital constante está constituido por animales y que la mano de obra «reemplaza» las máquinas y los equipos, es inútil invertir a largo plazo. La racionalidad del sistema supone que el aumento de capital obtenido al final del ciclo productivo no se haya gastado para adquirir bienes de equipo, ya que el adelanto de capital más rentable consiste en salarios. Es de semejante organización que los propietarios sacaban las mayores ganancias. ¿Por qué habrían de cambiar?, se pregunta el investigador francés. En cuanto a los beneficios que así proporcionaban, se escapaban de la unidad de producción para transformarse en bienes inmuebles (gran parte de los propietarios de las explotaciones mayores de 500 has encuestados en 1968 residían en Sevilla en un sector de «pisos de lujo») o en acciones, o más sencillamente para asegurar un nivel de vida elevado y la educación de los hijos. Encerrados en al práctica de un sistema inmóvil, los ganaderos permanecieron mayoritariamente «paralizados». Eran rentistas mucho más que jefes de empresa, concluye Roux (1975:239): 
«Ningún esfuerzo de selección genética sistemática, ningún trabajo para mejorar la producción forrajera, tampoco inversiones, ni siquiera para conservar los edificios. Las condiciones económicas tan favorables gracias a que el sistema pudo durar largo tiempo, han engendrado, muy naturalmente, unos ganaderos incompetentes, que no pueden asumir su propia transformación ni tampoco la de su ganadería.»

¿No es ésta, acaso, una de las claves que explican el atraso de la agricultura española: el no desarrollo de sus fuerzas productivas?

Por las características del sistema, la región se está quedando «al margen», escribe Roux, en lo que se refiere a las actividades agrícolas. Así, pues, se readapta: por un lado hacia la repoblación forestal, lo que no se podría criticar si la repoblación se efectuase conforme a un plan de asignación de las tierras estudiado según las potencialidades de los suelos, pero no ocurre así actualmente. Por otro lado, se orienta hacia las actividades cinegéticas, lo que choca más, ya que esas actividades, privilegio de algunos, conducen con frecuencia a la degradación, si no al abandono de la ganadería. Por lo tanto, concluye Roux, nos encontramos en una situación en que el capital, por no encontrar la rentabilidad que desea «normalmente», se aleja de una región que así pierde progresivamente el papel que debería tener en la economía nacional (Roux, 1975: 252).

Y así ha sido, pues la crisis de sistema agrario de la Sierra Morena lo que ha provocado es una evolución o cambio en la estrategia de los grandes propietarios, desapareciendo las relaciones de producción semiserviles (medianería, trabajo gratuito, etc.), pero sin decaer el poder económico de la gran propiedad. El control político de las instituciones del Estado le ha permitido seguir su proceso de acumulación mediante tres tipos de salidas: la repoblación forestal ${ }^{1}$, los cotos de caza y la especulación inmobiliario-turística.

Ya Roux lo intuyó a mediados de la década de los setenta: es lo que ocurre en zonas enteras del Andévalo, donde se practica la repoblación con eucaliptos, y en la Sierra, donde se encuentran algunas explotaciones transformadas en cotos de caza.

Muchos terratenientes, sobre todo los que tienen sus tierras en las zonas menos fértiles, en el Andévalo especialmente, han preferido vender o arrendar sus tierras a las empresas forestales antes que seguir con una ganadería que ya no juzgaban rentable. Están incitados por la política de repoblación forestal llevada por la empresa nacional de producción de pasta de papel (ENCE S.A.) situada en San Juan del Puerto, cerca de Huelva, en colaboración con el Servicio Nacional Forestal, y también por otras empresas privadas del Norte de España. Al deshacerse de sus tierras, los terratenientes han vuelto a encontrar una parte de la renta que ya no podía proporcionarles la ganadería extensiva, bien en forma de renta capitalizada por la venta de sus tierras, bien en forma de un arriendo anual. Se podía ver la importancia que este proceso tiene ya en 1970, pues las nuevas plantaciones ocupaban más de la mitad del territorio en cuatro municipios, entre el 30 y el $50 \%$ en seis municipios, y entre el 10 y el $30 \%$ en diez de ellos (Roux, 1975: 229). Desde entonces, superficies muy importantes se añadieron a esas primeras plantaciones. Sin embargo, hoy en día, parece que las empresas industriales tienen alguna dificultad en encontrar nuevas superficies.

1 La Ley de 8 de junio de 1957, de montes (BOE núm. 154, de 10-06-1957) ha sido considerada por muchos autores como una ley que contempla al monte en un sentido productivista, pero una lectura más pormenorizada y el estudio de la realidad de su aplicación muestra la mano de los grandes propietarios de tierras que a la vez eran grandes propietarios de montes, cuando los campesinos pobres y sin tierra comienzan a emigrar, utilizan al Estado para seguir cobrando la renta de la tierra (ya lo decía a principios del siglo XX un gran propietario catalán: «tierra que no haz de colonizar hazla repoblar»). 
Efectivamente, las tierras destinadas a la repoblación forestal no se pueden comprar a un precio demasiado alto sin que la rentabilidad de la operación esté comprometida. Otra fórmula, todavía a prueba en el momento que Roux realizaba su trabajo pero luego bastante extendida, ha sido la de cambiar las tierras por acciones de la sociedad, lo que en principio permitiría al terrateniente conservar su «capital» y recibir una renta correspondiente (los dividendos) (Roux, 1975: 231).

Una última fórmula utilizada por los grandes propietarios para seguir manteniendo la renta de la tierra, como consecuencia de la crisis de la dehesa fue el consorcio con el Estado. El consorcio tiene la ventaja de no desvincular al propietario de la explotación y, por parte de la Administración se necesitan menos fondos al no tener que adquirir la propiedad. El consorcio supone la propiedad del vuelo, pero no del suelo, o lo que es lo mismo «derecho a la madera en pie», aunque no se posea el suelo que la sustenta. Como explica Márquez, desde el punto de vista jurídico, la contratación supone una figura «sui generis». A primera vista reviste la forma de una aparcería, en la que el propietario aporta la tierra y la otra parte el capital y el trabajo, dividiéndose los rendimientos en el porcentaje estipulado, que para el eucalipto suele ser del $35 \%$ para el propietario y el $65 \%$ para la Administración, referido al aprovechamiento del arbolado, pudiendo el propietario beneficiarse de los demás aprovechamientos, leñas hojas, etc. (Márquez, 1977: 84). De las 147.000 has de montes administrados por ICONA de Huelva, 58.000 es en forma de consorcio y 76.000 en propiedad. Márquez corrobora la estrategia de la gran propiedad en lo que se refiere a la repoblación forestal, cuantificando en 200.000 las hectáreas de eucaliptal en la provincia de Huelva (Márquez, 1977: 63-78).

La crisis en la Sierra pronto genera otra alternativa de uso: el acotamiento cinegético (Roux, 1975: 201 y ss.; Valle, 1985: 484 y ss. y 1991; López y Valle, 1987 y 1989; López Ontiveros, 1986b; Rivera, 1992: 115-120; Mulero, 1991 y 1995: 304-307). En uno de los primeros artículos, si no el primero, en España sobre las posibilidades de la dedicación de grandes propiedades a la caza mayor, López (1972: 167) escribe que su trabajo está orientado hacia el estudio de este nuevo tipo de explotaciones [cotos de caza] que en Sierra Morena occidental han surgido con la finalidad de un mayor aprovechamiento de la riqueza que constituyen sus productos naturales. Y justifica su aportación diciendo que no existe en la bibliografía española trabajos sobre esta cuestión, queriendo dar a conocer la única forma posible mediante la cual muchas fincas mantienen su productividad, y lo que pudiera ser la única solución de otras muchas que actualmente tienen una productividad nula en la zona.

La dedicación de las grandes propiedades de Sierra Morena a cotos de caza también se presenta como una evolución de la estrategia de los grandes propietarios de seguir manteniendo la renta de la tierra a través de la política: la entrada en vigor de la Ley de Caza de 1970. El mejor trabajo que sobre este cambio de uso del suelo se ha realizado es la tesis doctoral de Mulero que estudia la génesis y desarrollo reciente de los espacios cinegéticoforestales en 33 municipios cordobeses que abarcan unos 9.500 kilómetros cuadrados.

Andalucía ha contado con una tradición cinegética bien arraigada históricamente (López Ontiveros, 1986b: 87-97). Como señala Mulero, en consonancia con la diversidad regional del sur peninsular, es posible hablar de una caza de campiña, de una caza de zonas húmedas y, en tercer lugar, una caza de montaña. Entre ellas, ésta última resulta espacialmente significativa, por cuanto marca las diferencias entre las ocho provincias andaluzas. Córdoba, Jaén y Sevilla, con mayor participación en Sierra Morena, son precisamente las que tienen mayor número de hectáreas acotadas, sobresaliendo las dos primeras en todo lo que a caza mayor atañe (634 cotos de caza mayor que abarcan una superficie de 930.000 has., extensión superior a la del archipiélago canario o al País Vasco). Tanto por sus aptitudes ecológicas, 
demográficas y de estructura de la propiedad, como por los efectos de la crisis agraria de la montaña española, esta gran unidad serrana ha adoptado entre sus aprovechamientos tradicionales al cinegético, convirtiéndose éste en auténtico monocultivo en algunas zonas (Mulero, 1995: 124-125).

La crisis de los aprovechamientos serranos comienza a solventarse con la aprobación de la Ley de Caza de 1970 y su Reglamento de 1971. El «boom» cinegético que se produce a partir de esta década está directamente relacionado con la adecuación de la estructura de la propiedad a los requisitos de superficie exigidos por la Ley de Caza (superficie de las explotaciones mayores de 500 has para formar un coto de caza mayor) claramente beneficiosa para el acotamiento de las grandes fincas serranas (Valle, 1977: 587-596; López Ontiveros, 1981: 289-290; Mulero, 1995: 80).

Mulero destaca, dentro de la tipología de espacios cinegéticos recogidos en la Ley de Caza, a) la casi inexistencia de terrenos de aprovechamiento cinegético común que posean aptitudes cinegéticas; b) el fracaso de los cotos locales de caza, cotos sociales de caza y terrenos de caza controlada (los dos últimos como parte del contenido social que los preceptos de la Ley de 1970 creó) y, por el contrario, c) la generalización de los cotos de caza privados, cuya consecuencia ha sido la extensión de la práctica de la caza a amplios territorios pero a pocos practicantes (Mulero, 1995: 84-90).

Otra tendencia que se ha ido generalizando con el paso de los años dentro de la categoría de los cotos privados son los cercados cinegéticos, convirtiendo a estas grandes fincas en auténticas explotaciones cinegéticas por parte de sus titulares (Mulero, 1995: 107).

La extensión de los cercados cinegéticos ha traído también consecuencias ecológicas negativas como es la esquilmación que buen número de los mismos, mal gestionados, están padeciendo en su suelo y en su cubierta vegetal, debido a una sobredensificación aguda de ejemplares, cuyo número supera como mucho la capacidad de carga de las fincas. Mulero ha constatado que, pese a los considerables ingresos brutos que se derivan de los cotos de caza mayor, los territorios donde estos se localizan vienen soportando una gestión cinegética obsoleta, con graves problemas de ordenación fruto del obstáculo que ha representado la pervivencia de un latifundio de sierra muy tradicionalista, reacio a aceptar sin reservas la existencia de defectos estructurales en sus explotaciones cinegéticas. Así, elementos tan importantes como la valoración de las características físicas y bióticas de los cotos, o la determinación de su capacidad de carga, han sido ignorados hasta nuestros días (Mulero, 1995: 322).

Por último, resta apuntar una serie de consecuencias negativas del proceso de acotamiento privado de cotos: la adquisición de fincas por extranjeros, considerable presencia de titularidad foránea en las explotaciones cinegéticas, la competencia que el turismo cinegético ha supuesto para los cazadores locales ${ }^{2}$, la escasez de terrenos de aprovechamiento cinegético común (libres donde practicar la caza), la patente desigualdad socioeconómica en el acceso a los cazaderos, pérdida de reputación de los cazaderos cordobeses, haciendo refluir el turismo cinegético, el blanqueo de dinero negro y el fomento de la economía sumergida (López Ontiveros y Valle, 1987: 89-92; Peña, 1985: 33-36; Mulero, 1995: 330 y ss.).

La mercantilización sin beneficios sociales se recoge en una encuesta realizada entre los habitantes del municipio de Hornachuelos (Córdoba) que concluía señalando que las dos terceras partes de los encuestados decían que la caza no tenía repercusión económica en el pueblo y tampoco generaba empleo (Mulero, 1991: 168-170).

2 Causa reciente del furtivismo que sigue siendo habitual en los municipios limítrofes de la Campiña cordobesa y sevillana (Mulero, 1995: 382). 
En síntesis, en la década de los cincuenta se documenta perfectamente en buena parte de Sierra Morena el dominio espacial de los aprovechamientos ganaderos extensivos. Sin embargo, desde finales del citado decenio, se hacen patentes los efectos negativos del fuerte éxodo emigratorio que afectó a la gran mayoría de los municipios cordobeses, así como de la repoblación forestal ${ }^{3}$, que también incidió con fuerza durante el citado período. El primer proceso está en la raíz de la escasez de mano de obra barata (primer pilar del éxito del sistema ganadero extensivo), así como de su encarecimiento; el segundo, provocó la prohibición de aprovechar el pastizal en los predios sometidos a repoblación por parte del Patrimonio Forestal del Estado, con la finalidad de salvaguardar los plantones de las especies de crecimiento rápido que se utilizaron. Ambos fenómenos dieron lugar a fines de los cincuenta, a un debilitamiento del sistema ganadero extensivo, del que se benefició directamente el aprovechamiento cinegético. A partir de este momento los cotos de caza comienzan a emerger con fuerza en la zona, como expresión de la voluntad de los propietarios de compensar, con este nuevo uso, las rentas perdidas tras el hundimiento del sistema ganadero tradicional (Mulero, 1995: 389-390). Es la evolución del sistema agrario serrano a parir de los años sesenta-setenta del pasado siglo.

La estructura agraria con base en el latifundio se sigue manteniendo hoy en la Sierra Morena, de tal manera que todo proyecto de racionalización del sistema agrario choca siempre con esta premisa. Rivera (1992: 108-109) explica este problema cuando intenta visualizar las posibles salidas al estancamiento ancestral de la Sierra. En su libro señala que en el caso de las grandes propiedades particulares, sus dueños suelen tener frecuentemente otras actividades dentro o fuera de Sierra Morena y al margen del sector agrario, convirtiéndose de hecho en absentistas que no buscan rentabilidad inmediata en sus tierras porque tienen otras fuentes de ingresos. En muchos casos se convierten en un lugar de recreo para el dueño, en zona de compraventa de ganado sin criar animales en la finca o bien están dedicadas a cotos de caza o abandonadas simplemente en espera de volver a venderlas. Para este tipo de propietarios comprar una dehesa es, además de una inversión, una cuestión de prestigio. Por ello mismo, no existe muchas veces un verdadero aprovechamiento de las tierras y puede hablarse propiamente de subexplotación. Sólo algunos grandes propietarios que han realizado nuevas inversiones con ayuda del Estado y que han integrado su explotación ganadera en un circuito amplio de abastecimiento y comercialización, practican una ganadería relativamente rentable.

Todo esto lo que confirma, en definitiva, es que la economía de estas grandes explotaciones se mantiene por recursos exógenos, según Rivera. Los grandes propietarios raramente lo son de una sola dehesa, sino que poseen otras fincas en el Valle del Guadalquivir u otras comarcas o bien la economía ganadera de estas propiedades acaba por integrarse en operaciones económicas extraagrarias (financieras, por ejemplo). Estas actividades no agrarias, pueden absorber, cómo no, las pérdidas de la explotación, pero de ninguna forma propicia la mejora de la misma, ya que ésta requiere no solamente inversiones arriesgadas y cuantiosas, sino también el control de un sistema de relaciones laborales que se les escapa de las manos.

Como consecuencia, concluye Rivera, la mayoría de agricultores y desempleados agrarios se ve abocado a la agricultura familiar, que al no asegurarles una renta suficiente les obliga a dedicarse parcialmente a muy diversas actividades (construcción, minería, servicios, obras públicas del P.E.R. o subsidio agrícola). Por tanto, mientras se mantenga el excesivo monopolio de la gran propiedad son muy escasas las posibilidades de transformación de la agricultura y la ganadería salvo en áreas muy puntuales de Sierra Morena.

3 Apogeo de la compra de montes por el Estado en la década de los sesenta (Mulero, 1995: 409). 


\section{La campiña y altiplanicies cerealistas}

En la Campiña del Guadalquivir donde predominaba el cultivo cerealista, la explotación de las grandes fincas se realizó hasta los años sesenta mediante la combinación de aparcerías en unas propiedades con el contrato de trabajo a jornal en otras (con partes del pago del jornal en especie, fundamentalmente la comida).

Determinadas faenas agrícolas se realizaban jornal y a destajo. Es necesario advertir que existía una gran relación entre trabajo a jornal y obrero fijo y trabajo a destajo y obrero eventual, pero que necesariamente no se trata de términos sinónimos. Sin embargo, el trabajo a jornal en estas grandes explotaciones se combinaba con el trabajo a destajo y otras formas de contratación que eran claras reminiscencias precapitalistas. Las investigaciones de Martínez Alier (1968) y López Ontiveros (1974), cuyos trabajos de campo fueron realizados en los años sesenta en plena modernización de la Campiña cerealista, no pueden negar la pervivencia de dichas relaciones de producción no recogidas en las estadísticas de la época: trabajo a destajo, barbechos a medias, parcelas de regadío, contrato de melones y contratos de ganadería. A ello hay que añadir la funcionalidad de los ruedos de los pueblos de la Campiña, en los que la pequeña propiedad había ido generando un campesinado minifundista, indispensable para suministrar mano de obra a los latifundios, como bien lo demuestra Mata (1987: 14-15):

«...las relaciones de interdependencia entre pequeños y grandes propietarios, una de las claves, sin duda, para comprender la viabilidad y «funcionalidad» del minifundio campiñés y, en general, toda la coherencia interna de la estructura de propiedad de la Campiña y Ribera béticas.»

Y aquí, es necesario salir del estricto marco geográfico de la Campiña si se quiere comprender la funcionalidad por lo que a la disponibilidad de mano de obra se refiere (campesinado pobre: pequeños campesinos y campesinos sin tierra) de las montañas que flanquean la Campiña tanto por el Norte (Sierra Morena), como por el Sur (Las Béticas y Subbéticas).

Son muchos y muy variables los factores que determinaban la existencia del trabajo a destajo en la Campiña hasta los años sesenta del pasado siglo: acumulación estacional de determinadas labores agrícolas que se deben efectuar en poco tiempo, escasez igualmente estacional de mano de obra, costumbre y posibilidad de reducción de costes «cuando los salarios aumentan y los rendimientos del trabajo disminuyen» por parte de los empresarios.

Siguiendo a López Ontiveros (1974), veamos cuáles eran las faenas agrícolas que en la Campiña se realizan a jornal y cuáles a destajo en el momento en que es redactada su investigación, sobre todo en relación a las tierras calmas y olivares, que constituyen la mayor parte de la superficie cultivada.

Para cualquier cultivo se realizan a jornal las labores de arado y las de sementera, en el cereal, la labra del algodón y, en el olivo, las de tala. En todo estos casos, aparte las razones citadas, que no hacen aconsejable el destajo, influye en la decisión un hecho fundamental: todas ellas son labores que de manera muy directa determinan la producción y que, por lo tanto, no se puede correr el riesgo de realizarlas mal, aunque ello resulte más barato. Por ejemplo, olivos mal talados pueden quedar inservibles para siempre, rastrojos mal levantados pueden no soportar otra siembra, sementera poco uniforme y poco densa disminuye la producción; con labra de algodón o escarda de cereales — cuando se realizaba a mano—- mal hechas, las hierbas dañinas no se arrancan, sino que simplemente se entierran, etc.

Las faenas más aptas para realizarse a destajo son las de recolección. La recogida de aceitunas y la siega a mano tradicionalmente se han realizado a destajo en cosechas nor- 
males o buenas. Sólo cuando son muy escasas pueden no acceder los obreros a esta forma de remuneración por dos razones: el trabajo a jornal prolongaría un poco más su ocupación y el destajo en estos casos «no conviene» porque los resultados económicos son malos. En tiempos actuales, según López Ontiveros, el sistema de destajo se ha extendido a otras recolecciones, como la de algodón, maíz, naranja y remolacha. En este último caso, no sólo su arranque, sino también su limpieza y carga. Hay otras labores en que el destajo también es normal: cava de pies y hacer hoyos, ambos para olivos; preparar tierras en surcos para riego; acarrear sacos de trigo de la era al cortijo o a los remolques, etc. En todos estos casos, el control de cantidad y calidad, en general, es factible. Y, por último, hay otra serie de faenas que acostumbran o no a darse a destajo, según las circunstancias, pero donde no es nada fácil asegurar que las tareas han sido bien hechas: por ejemplo, «gradear», labrar habas y garbanzos, abonado, aclare de algodón, escarda y entresaca del maíz, dar «planet», etc. En los grandes conflictos sociales de la Campiña, el destajo ha sido uno de los puntos más controvertidos, defendido por los propietarios e impugnado por los líderes obreros (Díaz del Moral, 1995: 353).

Es reconocido por diversos autores que en la década de los veinte y treinta del siglo XX muchas de las grandes fincas ubicadas en las fértiles tierras de la Campiña del Guadalquivir fueron parceladas y cedidas a arrendatarios y aparceros ${ }^{4}$ (Carrión, 1932: 243 y 345-346; Naredo, Ruiz-Maya y Sumpsí, 1977: 9). En el estudio de Cruz sobre Carmona, leemos que según el informe de Mariano Rodríguez Gutiérrez, notario de Carmona, a comienzo de la década de los treinta, sólo se explotaba directamente el $10 \%$ de las tierras, el $70 \%$ se encuentran arrendadas y el $20 \%$ se subarriendan (Cruz, 1980: 326).

Este fenómeno se prolongó hasta finales de los años cincuenta y principios de los sesenta de dicho siglo. El trabajo de Naredo citado anteriormente expone un ejemplo de cómo se parceló una finca de la Campiña de 1.500 has en 73 lotes de 20 has de superficie (olivar y tierra calma) en la que llegaron a vivir 700 personas. Además de la tierra de labor, el propietario facilitaba al colono una vivienda en la finca, le permitía sembrar en verde para alimentar al ganado de labor hasta el $2 \%$ del predio de la tierra calma que le hubiera correspondido y utilizar para «mataje» (como huerto de autoconsumo) la octava parte de una fanega. Asimismo, cada colono, además del ganado de labor necesario (normalmente dos mulos, una yegua o un burro), podía tener en la finca una cabra, un cerdo y una docena de gallinas. En lo que respecta a los gastos de explotación, corría por cuenta del propietario el gasto de semillas y abonos, así como los gastos generales y de administración y los impuestos. Por su parte los colonos estaban obligados a aportar la mano de obra, los aperos y el ganado de labor necesarios para llevar a cabo las labores de cultivo. Asimismo, los aparceros estaban obligados a entregar toda la cosecha al propietario, que se encargaba de medirla y colocarla en el mercado. La parte de la cosecha que le correspondía al aparcero, (el $50 \%$ ), le era entregada en dinero después de descontarle los gastos y amortizaciones de la maquinaria que el propietario había puestos a su servicio durante la campaña o de las labores que hubieran corrido a su cargo, así como los avances que le hubiera hecho el propietario para su consumo, el de su ganado o cualquier otra eventualidad (Naredo, Ruiz-Maya y Sumpsí, 1977: 14-15). Como se puede deducir, un ejemplo nítido de contrato

4 Martínez Alier aporta diversos ejemplos de expansión de las aparcerías en los secanos campiñeses en las décadas de los diez y veinte del pasado siglo (Martínez, 1968: 317). Cita como el vizconde de Eza introduce el sistema en Arcos de la Frontera y en Almodóvar del Río, en los nuevos regadíos del Pantano del Guadalmellato. También este autor transcribe como el 1919 el marqués de Torrenueva se refería a su descubrimiento. Aquí vemos como diputados y políticos españoles como el vizconde de Eza y el marqués de Torrenueva defendían estos contratos precapitalistas como solución al problema agrario en el Sur del país. 
precapitalista que pervivió desde la década de los veinte hasta principios de los sesenta, en el que hasta los aparceros vivían en el interior de la finca (endogamia, fiestas, celebraciones, como si se tratara de un pueblo cualquiera).

Por la importancia que tenían en la Campiña cerealista en los años que desarrolla su investigación, también el trabajo de Martínez Alier se ve obligado a dedicar todo un capítulo a las «medianerías» y «parcelas» (Martínez, 1968: 285-319). El autor justifica estos contratos leoninos presentando la medianería como una sociedad que beneficia tanto a propietarios como a medianeros.

Aparte de las formas de remuneración del trabajo asalariado y de las aparcerías en el secano campiñés, se utilizaron, en palabras de López Ontiveros, «una serie de imprecisas figuras jurídicas contractuales» para la explotación de las tierras. Éstas pueden resumirse de la siguiente forma (López Ontiveros, 1974: 471 y ss.):

$1^{\mathrm{a}}$. Barbechos a medias o «medianerías». El sistema de cultivo empleado en las tierras calmas campiñesas de secano era el de año y vez, con la existencia frecuente de barbecho semillado. En dicho barbecho se sembraba algodón, garbanzos, habas, maíz, etc. Ocurría con frecuencia que el cultivo de esas plantas de verano no se hacía directamente por el propietario, sino por un medianero mediante un contrato escrito o verbal que incluía las siguientes estipulaciones: la tierra es dada por el dueño convenientemente barbechada, o sea, con una reja de tractor, otra de «calificador» y gradeada y al él corresponde igualmente la elección del cultivo, la aportación de la semilla en su totalidad o sólo en un 40 o 50 por ciento, de la maquinaria y ganado de labor que se requiera y de los productos insecticidas. A su vez, al medianero corresponde aportar o realizar todo lo demás: mano de obra, siembra, labores, tratamientos fitosanitarios, recolección, envasados, acarreos y siega y quema de las matas si se trata de algodón. De los productos recogidos, el medianero se lleva el 40 por ciento - a veces el 50 por ciento-, y el dueño de la explotación, el 60 o el 50 por ciento.

$2^{\mathrm{a}}$. Parcelas de regadío: Como se indica en su denominación vulgar, se trata de un contrato que se da en grandes fincas de regadío, que divididas en parcelas, se toman por obreros - parcelistas - para sembrar en ellas sobre todo algodón, pero también remolacha y maíz. Al parcelista corresponde la realización de «cuantas faenas sean necesarias y suficientes para el cultivo» del algodón (u otras plantas), como se dice normalmente en los contratos, a saber: arreglo de machos y regueras, siembra, resiembra y aclare, las labras o escardas, abonado de cobertera, riegos, tratamientos que se deban dar con máquinas transportadas a brazos y las cargas de los aviones cuando el tratamiento sea aéreo. Y al propietario se reserva la dirección de los trabajos, y de su cuenta corren la recolección, transporte y siega y quema de las matas.

La remuneración del parcelista se realizaba mediante un sistema mixto de salarioparticipación en los beneficios que se articula de la siguiente forma: el parcelista recibe diariamente un jornal mínimo que tendrá el concepto de adelanto, caso de que la participación final sea superior, y una retribución proporcional al importe del producto recogido, que se fija mediante una escala móvil, en la cual su parte correspondiente va aumentando progresivamente en relación con el aumento de kilogramos de producto que corresponden a cada hectáreas cultivada. Se trata, en definitiva, de una aparcería en riego.

$3^{\mathrm{a}}$. Contrato de melones: Es también una forma de cultivar los barbechos de secano con las «medianerías» descritas anteriormente. El origen de este contrato primitivamente no tenía el carácter de una forma sistemática de aprovechamiento de los barbechos que revestía en los momentos que se redacta la obra. Era corriente en la Campiña «dar tierra para melones» - y a veces también para ajos, habas y garbanzos-, siempre en pequeñas parcelas, a obreros del cortijo, con mucha frecuencia caseros y aperadores, que recogían 
los melones «para el gasto» o, todo lo más, para vender algunos en el mercado del pueblo. De tales melones correspondían al dueño algunos, normalmente también los necesarios para su consumo (Díaz del Moral, 1995: 409).

Escribe López Ontiveros que en tiempos muy recientes — años cincuenta y sobre todo sesenta_, ante la gran demanda y posibilidad de transporte a distancia de estos melones, junto con la aparición de nuevos tipos de los mismos que «aguantan mucho» - melones de exportación-, se ha generalizado su cultivo en los barbechos campiñeses, sobre todo por obra de los meloneros de Montalbán, que cada año se dispersaban por la Campiña demandando tierra para sembrarlos. Como era de esperar, los propietarios no han desaprovechado la oportunidad lucrativa que les brinda esta demanda y se ha generalizado con tal fin un nuevo contrato para aprovechar los barbechos, cuyas principales características resume el propio autor. En estos contratos, el propietario entrega la tierra barbechada, y todas las demás labores y recolección corren de cuenta del melonero. El contrato leonino de melones constituye siempre un lucrativo negocio para el propietario, dados los altos precios que se pagan por las parcelas, $y$, desde luego, es la quintaesencia de la ausencia de riesgo en el cultivo cuando, inexorablemente, a la firma, se entrega la totalidad de la renta. Lo normal es que las parcelas que se toman para este contrato sean de 30 a 50 fanegas, o incluso menores, o sea, una superficie de tierra que puede cultivarse por sólo el melonero ayudado por su familia.

$4^{\mathrm{a}}$. Con ganado del dueño puede existir otro tipo de contrato, poco frecuente según López Ontiveros, en el que su objeto lo «constituye todo el trabajo necesario para la guarda y cuido» de un rebaño. Según el contrato preciso que Martínez Alier (1968: 398) incluye a este respecto en su obra, en las poblaciones carolinas y en especial en La Carlota, dadas sus especiales características ganaderas, son muy frecuentes contratos de aparcería pecuaria de ganado vacuno, lanar y de cerda. Se entrega una vaca o pequeños rebaños de cerdos y ovejas, a un aparcero por dos años, al término de los cuales se devuelven al propietario junto con el importe en metálico del $50 \%$ de las crías o lana que se hayan obtenido en ese tiempo. En caso de que no se puedan devolver los animales reproductores, por muerte o sacrificio debido a causa mayor, el aparcero ha de pagar al propietario el $50 \%$ de su valor. Incluso son objeto de aparcería aquí las pavas, de Navidad a Navidad, fecha en que se entrega la renta, que es un pavo macho, y se devuelven las pavas. El obrero recibe mensualmente una retribución mínima - 60 céntimos por cabeza y día, más el 15 por ciento del producto neto que dé el rebaño cuando se venda (que se hallará restando el valor bruto los piensos que se consuman, el valor de montaneras y espigas, gastos de veterinario, vacunas, etc.).

Para determinar la importancia cuantitativa que todas estas figuras jurídicas mixtas tienen en la Campiña de Córdoba, no se poseían datos de ningún tipo. El carácter estacional y siempre temporalmente limitado de las mismas, así como, muchas veces, su carácter verbal, son las causas de esta falta de estadísticas. No obstante, de forma general se puede afirmar que son muy escasos los contratos de ganadería, y, sin embargo, tenían todavía muchísima importancia hasta los años sesenta del siglo XX los restantes. Según Martínez Alier, que tan extensamente los ha estudiado, en 1964 el 30 y el 5 por ciento de los barbechos del extenso término de Córdoba, respectivamente, se sembraban mediante medianerías para plantas de verano y para melones; en La Rambla, a ambos contratos conjuntamente correspondían cantidades entre el 80 y el 50 por ciento de sus barbechos, y, en Cañete, esta cifra estaría también alrededor del 50 por ciento. A su vez en regadío, opina este autor que la mitad del algodón y remolacha está en manos de parcelistas (aparceros).

Concluye el geógrafo andaluz señalando que estas cifras, aunque aproximadas, son más que suficientes para justificar la detallada descripción que de ellas aquí hacemos, ya que, de seguro, en el total de la Campiña tiene mucha más importancia que las aparcerías 
propiamente dichas y «otros regímenes de tenencia», y en algunas zonas incluso más también que los arrendamientos permanentes reflejados en los datos del Censo Agrario (López Ontiveros, 1974: 477).

También en las altiplanicies interiores de las cordilleras Béticas pervivieron, e incluso se acrecentaron, los regímenes de tenencia precapitalistas que provenían del Antiguo Régimen. Así parece deducirse de la investigación de Ferrer sobre la Tierra de Alhama en Granada (Ferrer, 1982: 497). Cano, en su estudio de la comarca granadina de Baza (Cano, 1975: 343), escribe que, por lo que se refiere a la naturaleza de la renta, ésta suele ajustarse en especie en previsión de contratos largos que desvaloran progresivamente el alquiler: en los secanos, los olivos (incluso en riego eventual) y almendros suelen darse a medias, y para las tierras de cereal y leguminosas, lo usual es la aparcería. Cano advierte también de diversas prácticas poco estudiadas, pero de claras reminiscencias serviles (Cano, 1975: 343):

«Por último, señalar que el algunos aspectos perviven ciertas tradiciones, como la cobranza en especie de las aventadoras y, con frecuencia, de las trilladores, que suelen hacer el trabajo a cambio de la paja, costumbre ésta muy arraigada en toda la comarca para tales faenas y que aparece consignada en la Cartilla Evaluatoria de Zújar (1851), varias veces citada, donde en la contabilidad de cereales se dice «era y trilla por la paja».»

Una parte de la economía terrateniente de la Campiña se «disfrazó» de moderna con la mecanización del cultivo cerealista (combinado con su decantación final por la oleaginosa girasol) a partir de la crisis agrícola de los años sesenta. Y es que la emigración de los jornaleros obligó a la mecanización del cereal, pues dicha mecanización pudo haberse realizado muchas décadas antes. No obstante, esta aparente modernización se hace en un momento en que la evolución de la técnica agronómica permite visualizar un horizonte campiñés que ya no correspondía al monocultivo cerealista, sino al futuro vergel bético que la gran propiedad no podrá acometer. De ahí las quejas del jornalero campiñés que no vienen sino a reflejar el no desarrollo de las fuerzas productivas en las mejores tierras del país:

«Las extensiones grandes de tierra que es donde nosotros pedimos que se siembre alcachofas, pimientos, espárragos, esos cultivos requieren mano de obra, pero lo que hay sembrado en estos momentos son cosas que no dan mano de obra ninguna, solamente maquinaria y, sobre todo, utilizan la tierra solamente para la subvención, no la utilizan con el objetivo de crear riqueza, no; ellos tiran allí la siembra y después cobran la subvención y punto, no les interesa nada más.» (ANDRÉS BÓDALO, jornalero y miembro del S.O.C., Jódar —Jaén—, 3/4/03)

\section{Los regadíos béticos}

Hasta los años treinta del pasado siglo no pudo ir expandiéndose el regadío (existen numerosos ejemplos de grandes propietarios que no querían introducir el regadío ni en sus tierras ni en las de los pequeños propietarios). Pero, cuando finalmente se van implantando las infraestructuras de riego en las tierras de la gran propiedad, se hizo a costa de la instalación de pequeños colonos mediante fórmulas de contratación semiserviles: pagos en especie (aparcería) o arrendamientos «leoninos».

Sobre la oposición al regadío resulta ilustrativa la siguiente reflexión de León, a propósito de las obras de ampliación del regadío en el bajo Genil que afectaban al municipio 
cordobés de Palma del Río que él estudia. León escribe que la República encontró muchas dificultades para llevar adelante los planes de regadío establecidos (León, 1990: 67). Una de las principales la constituían los grandes propietarios. A parte de consideraciones políticas, señala este autor, debemos tener en cuenta otras que, no por menos evidentes, dejan de ser ciertas: la mentalidad de buena parte de los grandes propietarios de la época les hacía recelar de todo aquello que supusiera un cambio importante en la forma de administrar su propiedad. Dentro de ellos hacían y deshacían de acuerdo con su mejor criterio; en definitiva, dominaban la situación, se sentían dueños de su tierra en sentido amplio de la palabra. León señala que pasada la Guerra Civil, y tras la puesta en riego de importantes superficies dentro del término municipal cordobés de Palma del Río, se abrieron nuevas expectativas económicas que aprovecharon muy bien los grandes propietarios en un contexto de sobreabundancia de mano de obra. Pequeños y medianos labradores se vieron abocados a un régimen de aparcería impulsado por el mayor propietario de tierras, Moreno Ardanuy y su hijo Félix Moreno de la Cova en la finca «La Mallena». En él se estableció que el porcentaje sobre la cosecha que pertenecía al propietario rondara alrededor del 30 $\%$ aproximadamente (León, 1990: 57).

También las obras de infraestructura en el río Guadalmellato pusieron en riego extensas fincas en los municipios de Córdoba y Almodóvar del Río. Torres ha estudiado en esta parte de la Vega del Guadalquivir el proceso de implantación del regadío a lo largo de todo el siglo XX. Los grandes propietarios se interesaron en la transformación en regadío de sus latifundios sólo a partir de los años finales de la década del veinte y del treinta, viendo con buenos ojos la posibilidad de mejorar los rendimientos de los mismos. Sin embargo, esa transformación no estaba exenta de la necesidad de inversiones muy elevadas en materias como la terraplenación, construcción de canales, intensificación de las labores, mano de obra, etc. Estas circunstancias favorecieron que los grandes propietarios potenciasen, con el inicio de los riegos, la parcelación y explotación indirecta de los lotes, cargando sobre los arrendatarios buena parte de los costes y la responsabilidad de la transformación en regadío. De esta forma, si a principios del siglo XX la explotación indirecta (aparcería y arrendamientos leoninos) ya era común en la Zona Regable del Guadalmellato, con la proximidad de los riegos o su inicio, ésta se potenció y extendió por la mayor parte de los grandes latifundios e incluso en la pequeña y mediana propiedad de los ruedos cordobeses y almodovarenses. Con ello los propietarios conseguían fáciles rentas, la transformación somera de sus tierras y, al mismo tiempo, justificaban su interés por la colonización agraria, el paro agrícola y otras lacras del mundo rural a finales de los veinte y principios de los treinta (Torres, 2002: 64).

El propio Carrión escribe que para 1932 el canal principal del Guadalmellato dominaba unas 4.000 has de la Vega del Guadalquivir, si bien sólo se regaban de forma efectiva 1.000 has y 700 de ellas se hacían bajo contrato de arrendamiento poco favorables para los colonos y para el desarrollo económico de la zona (Carrión, 1935).

Pasada la etapa del reformismo republicano y la propia Guerra Civil, ¿qué sistema de explotación fue el dominante? En la primera mitad de los cuarenta y gracias a los datos del Proyecto General de Colonización del INC, no cabe duda de que la explotación indirecta siguió manteniendo su representatividad de antaño, consolidándose el modelo de arrendamiento e iniciándose una progresiva expansión de la aparcería (Torres, 2002: 65-66).

Atendiendo al censo de cultivadores del Proyecto de Colonización, Torres estable la existencia de un total de 1.038 cultivadores en la Zona Regable. El grupo de explotadores directos representaba sólo el $23 \%$ del censo; mientras que por el contrario, los explotadores indirectos o colonos, alcanzaban nada menos que el $77 \%$ de los cultivadores, siendo el porcentaje de arrendatarios muy superior a un testimonial 8,09 \% de aparceros. En lo 
que respecta a la distribución del sistema de explotación según superficie cultivada, la explotación directa se lleva a cabo en un $27 \%$ de las tierras, mientras la indirecta agrupa al $73 \%$ siendo, por supuesto, el arrendamiento el tipo más común de la zona. A la vista de las cifras referidas la explotación indirecta seguía siendo la constante en el sistema de cultivo en el Guadalmellato. En lugar de disminuir como consecuencia de las numerosas críticas vertidas a lo lardo de los primeros años de la década de los 30, el arrendamiento de tierras utilizando contratos a corto plazo siguió siendo una constante que incluso se potenció aún más con motivo de la expansión del riego. Por último, a pesar de la general invariabilidad detectada en el inicio de la década de los cuarenta en materia de explotación, sí cabe mencionar el inicio de un progresivo interés por el desarrollo de las aparcerías, ya que la difícil situación económica del país hacía más estable y ventajoso para los grandes propietarios el empleo de rentas en especie (Torres, 2002: 66).

Los arrendamientos leoninos en el regadío no eran, ni mucho menos, capitalistas. Al respecto, resulta harto esclarecedor la precaria situación social de las familias de arrendatarios y aparceros en el nuevo regadío de la Vega del Guadalquivir en dos aspectos fundamentales como eran la vivienda y la salud.

Los contratos leoninos y la aparcería no fueron ajenos tampoco a las áreas de regadío tradicional de las vegas interiores andaluzas. Cano (1975: 345), en su estudio de la comarca de Baza (Granada) argumenta que predomina el arrendamiento, que suele ser de 4 fanegas de trigo (unos $170 \mathrm{kgs}$ ) por cada una de tierra (alrededor de 0,17 Ha), es decir 10 Qm/Ha; y que la aparcería presenta múltiples formas según el propietario reciba la mitad o el tercio de la cosecha. En el último caso, aquél aporta la tercera parte del abono, además de la tierra. Cuando la partición de productos se hace por igual, las aportaciones de cada uno son muy diversas, desde el dueño que sólo da la tierra (antes se acostumbraba bastante, ahora cada vez menos) hasta el que lo pone todo, excepto el trabajo, y casos hay en que ni aún así se demandan terrenos. Con todo, lo más general es proporcionar la tierra y la mitad de abonos y semillas. El arbolado existente dentro de las propiedades también es objeto de diferentes acuerdos en relación a diversas circunstancias: elevar la renta para incluirlos, dejárselos al colono, si se trata de unos cuantos frutales, o separarlos del contrato quedando para el dueño. También se acostumbra arrendar la tierra y dejar las frutas a medias, o hacer esta partición en ambas cosas.

Las políticas de colonización del Estado han constituido otra de las estrategias que la gran propiedad — tanto pública, como privada - ha desarrollado para, mediante la generación de un pequeño campesinado, disponer de mano de obra barata para emplearla en sus explotaciones. En el estudio de la Zona Regable del Viar, a unos $20 \mathrm{kms}$ al Norte de la ciudad de Sevilla con 2.300 has que se distribuyeron entre 397 colonos, entre 1953 y 1957, parece comprobado, según sus autores (Cruz; Ojeda y Zoido, 1980: 12), que las explotaciones de colonización poseen una serie de rasgos comunes, entre los que destaca la orientación extensiva dada a las tierras, las reducidas dimensiones de las parcelas de colonización, una producción baja y unos beneficios insuficientes; el resultado es que la explotación va dejando de ser familiar, en el sentido de que es incapaz de retener la propia fuerza de trabajo. En el último estado de esta evolución, el mismo empresario se emplea como jornalero e incluso, en casos que cada vez comienzan a ser más frecuentes, adquiere un empleo fijo en la agricultura, la industria o los servicios.

En el caso del Viar, en los dos colectivos (propietarios libres y colonos) se vende la propia fuerza de trabajo y en ambas el empleo exterior significa algo más del 30 por 100 del tiempo de trabajo total medido en jornadas. Destacan los autores de la investigación que todos los tipos de componentes de la fuerza de trabajo familiar se emplean fuera de la explotación propia; casi el 50 por 100 de los empresarios o titulares de las explotaciones; 
el 80 por 100 de los hijos y prácticamente la totalidad del resto de los activos familiares (esposas e hijas principalmente). La agricultura es la principal fuente de empleo exterior para esta fuerza de trabajo (43 por 100), particularmente en la condición de eventuales (41 por 100 del empleo exterior o alternativo y 96 por 100 del agrario) (Cruz, Ojeda y Zoido, 1980: 48-49).

El trabajo encabezado por Cruz Villalón concluye señalando la baja productividad de esta agricultura familiar, el escaso desarrollo de las fuerzas productivas) y la progresiva tendencia de los colonos a ingresar en el estatus de jornalero:

«En conjunto, la operación colonizadora, basada en unos criterios fijados a priori y en un cierto esquematismo planificador, ha llevado, casi treinta años después de iniciarse, a una situación falta de dinamismo, prácticamente colapsada (esto lo expresa bien la alta proporción de pensionistas existentes entre los titulares), que contribuye a diferenciar a los dos colectivos de campesinos estudiados; todos los aspectos negativos aparecen siempre en mayor medida entre los colonos: disponen de peores y más reducidas tierras, trabajan más, ingresan menos $y$, en definitiva, están más cerca del jornalero...

Las explotaciones familiares siguen orientaciones caracterizadas por una corta alternativa, por la íntegra comercialización de los productos, por la mínima presencia de la ganadería — prácticamente desarticulada de la producción agrícola, cuando existe- y, sobre todo, por la subutilización de sus potencialidades productivas.»

Finalmente, se preguntan los autores: ¿por qué estos campesinos no han hecho aquí el esfuerzo de aumentar la productividad de sus tierras y gozar con ello del estatus caracterizado por la independencia económica que, en general, se atribuye a este grupo social? Esta estrategia es patente en otras partes y las tierras de la zona estudiada tienen amplias posibilidades para ser su soporte material. La respuesta es que estamos ante campesinos no libres.

Los resultados de un siglo de implantación del regadío en Andalucía no han conseguido convertir esta tierra en el modelo levantino. Muchos son los autores que concluyen la relación directa que ha existido y existe entre el fracaso del regadío y las estrategias de la gran propiedad.

Así, Ocaña señala que aún se confirma más esta apreciación ante el uso que la gran explotación hace de sus nuevos regadíos, sobre los que realizan sistemas muy similares a los del secano. Señala la autora que los frutales son parte minoritaria de estas explotaciones, y únicamente cuando la rotación del regadío se continúa en una ganadería intensiva, se aprecia una productividad intensificada del factor tierra. La gran explotación campiñesa incluye una fracción importante de tierras regadas: de Córdoba a Cádiz, unas 800 explotaciones reúnen 183.000 has de regadío, como nuestra inequívoca de los resultados de la Política de Colonización... para las grandes propiedades. Quizás el que la puesta en regadío se efectuara con fondos públicos y que ello se justificara por su función social, es lo que hace más condenable, según Ocaña, un aprovechamiento del regadío mucho menos intensivo que en las vegas tradicionales (1987: 58-59).

Torres, en su estudio sobre la zona regable de la Vega cordobesa del Guadalquivir, es tajante en sus conclusiones y escribe que desde el principio del regadío y a lo largo de su historia, el Guadalmellato no ha desarrollado un modelo de aprovechamiento agrícola de corte levantino. Las hortalizas o los cultivos permanentes no han llegado a alcanzar superficies significativas, destacando, al contrario, un franco predominio de los cultivos herbáceos 
anuales. Tal circunstancia se debió, según este autor, a la conjunción de varios hechos. Los más significativos han sido: el predominio histórico del latifundio, la aplastante presencia de explotaciones indirectas, el reducido riesgo agrario que los agricultores de la zona han estado dispuestos a asumir, el protagonismo de una política empresarial conservadora y oportunista según la situación anual de los mercados y la política de subvenciones agrarias (Torres, 2002: 1058)

Cuando estudia la comarca malagueña de Antequera, Mata (1979: 34) también concluye que en los llamados riegos nuevos dominan cultivos y sistemas semejantes a las tierras de sembradura de secano.

Los trabajos anteriores ofrecen ejemplos del dispendio del regadío en el Valle del Guadalquivir, del escaso desarrollo de las fuerzas productivas en las tierras más fértiles no ya de Andalucía, sino de España. La causa de la escasa transformación de este sistema agrario está en la pervivencia del latifundio, bajo la estrategia del control político de los grandes propietarios.

\section{El olivar de las subbéticas}

A medida que, quien recorra el Valle del Guadalquivir, se traslade en dirección Sur, el paisaje se va haciendo cada vez más montañoso; se deja atrás la Campiña y se entra en la cordillera de las Subbéticas, divisoria natural de la margen izquierda del Valle. Sobre estos terrenos calizos y quebrados el dominio en los cultivos pasa a ser del olivar, llegando a convertirse en monocultivo en comarcas enteras.

Hasta la crisis de los años sesenta, una parte de este espacio ha sido estudiado en profundidad por F. Ortega (1975) en un libro ya clásico que investiga la comarca cordobesa de las Subbéticas.

Según Ortega (1975: 17-35, vol. II), cuando comienza el siglo XX, el furor de las roturaciones se muestra en el descenso del terreno inculto que son el erial y el matorral (y no monte alto) procedente de las dehesas. Y este monte alto no se rotura sino ya por los particulares en el primer tercio del XX. Pero esta ocupación agrícola era débil y poco productiva en amplias zonas de la comarca, utilizadas para el cultivo extensivo de cereales y labradas en su mayor parte por aparceros y arrendadores, imposibilitados para promover un cambio de dedicación del suelo con el consiguiente aumento de riqueza, necesaria para mantener una población expansiva y proletarizada. Efectivamente, en las Subbéticas cordobesas, el paso de un paisaje inculto a otro de monocultivo olivarero, se hizo desde finales del siglo XIX, generalmente, tras una etapa de predominio o al menos de gran importancia de las tierras de sembradura anual y otra de policultivo posterior.

Las relaciones de producción en el olivar también fueron una combinación entre el trabajo asalariado (en muchas ocasiones a destajo) y el sistema de pago en trabajo. Ortega, al referirse a los arrendamientos todavía en los años setenta del pasado siglo, escribe que las condiciones, que se plasman en un contrato privado suelen ser el pago de un canon anual por aranzada (0,37 has) o por fanega ( 0,62 has). El canon puede ser en metálico - 1.200 pesetas por aranzada en Cabra (año 1970) — o en arrobas de aceite — 3 a 3,5 arrobas por aranzada (unos 35 kilos) (Ortega, 1975: 151, vol. II).

Respecto a la aparcería, este autor señala que la misma es la forma de explotación más numerosa y también la que presenta modalidades más variadas, a veces muy complejas, reflejándose en los contratos las condiciones más curiosas, como son las de aprovechamientos de productos secundarios dentro de una finca de olivar (aceitunas para aderezo, leña), o regímenes de utilización de otros cultivos existentes dentro de la explotación, como por ejemplo frutales, huertas, calmas, etc., para cada uno de los cuales hay varias cláusulas que 
lo reglamentan hasta el más mínimo detalle. Otras veces el contrato escrito es muy simple, pero, en ese caso, los posibles aprovechamientos de riqueza dispersa o productos secundarios se hallan igualmente regulados por la costumbre o son establecidos verbalmente.

El canon en aparcería es siempre una parte del producto. En el caso de fincas de olivar, en la década de los sesenta del siglo pasado, lo normal era la medianería estricta en cuanto al reparto del producto principal; el aparcero ponía su trabajo, yuntas y aperos, así como la totalidad o parte (a convenir) de los abonos y productos fitosanitarios. Al dueño correspondía el pago de los impuestos y la parte correspondiente de los abonos y los productos del «sulfatado» así como los gastos de la poda, que, dada su importancia para la buena marcha y conservación de los olivares, ha preferido hacerla y pagarla, antes que dejar esa faena en manos de desconocidos o inexpertos, a no ser que el propio aparcero fuera buen «talaor», en cuyo caso el dueño cedía algo más en otros gastos, como abonado o «sulfatado», como compensación al trabajo del aparcero-podador.

Pero desde que se inició la emigración, como sucedió también en los otros agrosistemas analizados, que afectó en cierta medida a los «medianeros» (aparceros, por extensión) especialmente a los más modestos, y se encarecieron los jornales ${ }^{5}$, los porcentajes exigidos por los escasos aparceros son cada vez más elevados. Como en otras muchas cuestiones, escribe Ortega, la zona de Cabra y Lucena se adelantó a la porción más aislada y montañosa del Este, y ya en 1970, los porcentajes de aceituna normales para el aparcero egabrense o lucentino eran del 60 al 70 por 100, mientras en Priego en ese mismo año lo normal era la medianería estricta, si bien hoy, en 1973, la proporción ha llegado a ser del 40 por 100 para el dueño y 60 por 100 para el aparcero, aunque en algunos pagos especialmente productivos se encuentran todavía aparceros que se conforman con el 55 por 100. Todo esto referido al olivar, que como hemos dicho repetidas veces es el cultivo básico. Cuando la finca incluye calmas o pequeños trozos de riego por manantial o pozo, las primeras se explotan «al tercio» (1/3 para el dueño), y con los regadíos se hacen complejos repartos entre productos de suelo y vuelo. Otras veces, el dueño renuncia al producto de los enclaves de calma o sólo recibe hortalizas y frutas «para el gasto», a cambio de un mayor porcentaje en la cosecha de aceituna o de la participación del aparcero en el pago de los impuestos (exclusivamente los de guardería y tratamiento obligatorio de plagas) o en la poda, aunque ésta sea dirigida y vigilada por el dueño (Ortega, 1975: 153, vol. II).

La forma de efectuar el pago es generalmente a través de alguna almazara, que, al llevar el aparcero la aceituna, expende dos vales, uno para cada parte contratante, por la cantidad de aceituna que resulte de la proporción previamente establecida en el contrato.

No era la aparcería la única relación precapitalista que Ortega encuentra en las Subbéticas cordobesas de los años sesenta y setenta del pasado siglo. Aunque se dispone de una muy escasa bibliografía, existe otro tipo de carga, escribe nuestro autor, que gravita sobre algunas tierras y que es sobremanera abundante en el partido judicial de Priego de Córdoba - como en otras partes de España-, el censo enfitéutico o enfiteusis, que aquí aparece no en su especie o clase alodial u ordinaria, sino en la propia del derecho señorial, aunque tras una serie de transformaciones ha derivado hacia formas no ya de enfiteusis ordinaria, sino incluso ordinaria mermada. «Es más malo que un censo» dicen los campesinos del Sur de la provincia de Córdoba cuando quieren reforzar la afirmación de mala calidad de cosas o personas. El valerse del censo como término de comparación supone la vivencia de unos hechos de carácter jurídico y profundas raíces histórico-señoriales que en esa zona

5 Aumento jornales: 475 por 100 aproximadamente. Aumento precio del aceite: 210 por 100 aproximadamente (Ortega, 1975: 145, vol. II). Es la expresión en los precios de la crisis del olivar en esas décadas de los sesenta-setenta del siglo pasado. 
han abundado sobremanera en el pasado y que no han desaparecido todavía cuando Ortega escribía sobre el tema. El pago de la renta se estableció en especie, concretamente trigo y cebada, con lo cual no sufría deterioro con el tiempo. De todas formas, cuando en los años de escasez de la posguerra subieron en exceso los granos, los enfiteutas consiguieron la desaparición del «patrón grano», congelando el precio del mismo, que ha quedado fijo desde entonces, con lo cual se inició la depreciación progresiva de la renta.

La enfiteusis representaba la pervivencia de una época de «sumisión señorial» que todavía en esos años suponía una carga para los pequeños agricultores olivareros de estas tierras serranas. Ortega (1973: 715) lo expresaba así:

«El hecho base que importa reseñar es que la liberación de los predios nobiliarios no ha sido completa. La renta es una realidad social histórica lamentable y lamentada, porque es la demostración periódica de una posesión incompleta de la tierra - ide una tierra cuya contribución estatal se paga!_, el recuerdo de una época de sumisión señorial y de miseria. Pero, aparte de estos inconvenientes que podríamos calificar de «sentimentales», aunque reales, existen también la rémora económica: la renta es un capítulo más de los costos de explotación de un sinnúmero de «propietarios», muchos de los cuales son de condición modesta y soportan un nivel de vida muy pobre, a pesar de que han convertido las malas tierras-calma de Medinaceli en magníficos y bien cuidados olivares. Las causas de esta pobreza son múltiples, destacando la pequeñez de sus tierras; pero es obvio que cualquier carga contribuirá a deteriorar el nivel económico. Los censos no son en este sentido una excepción ni mucho menos.»

Si la gran propiedad no desarrollaba las fuerzas productivas, otro extremo limitante de la productividad del olivar es el de los miles de pequeños olivareros. Los ingresos de estos últimos no se limitaban a las ganancias obtenidas de esos pequeños trozos —en plural para cada persona: parcelación-, puesto que es insuficiente, sino que poseen además otras tierras dedicadas a producciones complementarias dentro de un sistema económico cerrado, o trabajan para otros esporádica o estacionalmente, bien en la comarca, bien fuera de ella. Estos últimos podrían muy bien llamarse olivareros-jornaleros, por comparación a los propietarios-jornaleros, o tal vez — válido en muchos casos-, olivareros-emigrantes (Ortega, 1975: 164, vol. II).

Es en el olivar donde mejor se expresa la crisis de la economía terrateniente en los años sesenta de la centuria pasada. Ortega (1975: 165, vol. II) sintetiza de forma magistral cuando escribe la frase «desbandada de los jornaleros: se tambalea la gran empresa».

Aquí radica la onda trascendencia que para el olivar andaluz tiene la figura del jornalero. En estos años de crisis agrícola, al gran propietario sólo se ronda una idea: ¿cómo retener, cómo atar la mano de obra suficiente para poder seguir explotando sus grandes fincas olivareras, fincas que no permitían una mecanización absoluta como la realizada en la Campiña cerealista? El jornalero, huyendo de los regímenes de tenencia semiserviles, emigró hacia las áreas urbanas e industriales del Norte porque allí «lo trataban como a un hombre». La solución de los grandes propietarios fue recurrir a la instancia estatal que creó un sistema de prestación social singular para Andalucía a partir de 1971: el Empleo Comunitario y, posteriormente, el P.E.R.-Subsidio Agrario. 


\section{El valle del Guadalquivir: las interrelaciones de los sistemas dehesa - sierra - campiña - béticas}

Las interrelaciones, muchas veces de dependencia, entre los sistemas agrarios de Dehesa, Sierra y Campiña cuentan con numerosas referencias (Mulero, 1995: 255) pero sigue siendo un fenómeno que adolece todavía de suficiente evidencia empírica. En tal sentido, Valle afirma que la generalización de la aparcería en las explotaciones mayores, la abundancia de mano de obra y otras circunstancias favorables de índole agroclimática y económica permitieron a los grandes propietarios una rápida capitalización, en base a la cual prosiguieron la compra de tierras en Sierra Morena y, especialmente, en el Valle del Guadalquivir. Surgieron así unas explotaciones mixtas dehesa-sierra-campiña ${ }^{6}$ muy compacta en el contexto de las prácticas agrarias extensivas, que se articulaban en torno a los siguientes conjuntos de parcelas: las radicadas en el medio granodiorítico — germen de la explotación—, las adquiridas durante la desamortización civil —ubicadas sobre el granito o la pizarra — y las compradas en la Campiña y Valle del Guadalquivir (Valle, 1985: 269).

Su pertenencia a una misma explotación permitía, al mismo tiempo, el aprovechamiento individualizado de cada parcela conforme a sus cualidades agronómicas (cereal, olivar, pasto) y el aprovechamiento integrado a nivel agroecológico, del cual se benefició ampliamente la ganadería, pues contaba con la extensión y la diversidad espacial necesarias para la práctica de la trasterminancia. El ganado ovino y vacuno pasaba el otoño e invierno en las fincas ubicadas en Sierra Morena. Cuando se agostaban los pastos, a finales de primavera, regresaban a las dehesas, o vacas, ovejas y cerdos, bajaban a los espigaderos y rastrojeras de la Campiña. A comienzos de otoño regresaban a la sierra, a excepción del ganado porcino que iba a la dehesa para aprovechar la montanera. Cuando la explotación contaba con alguna finca de olivar y en ella existía almazara, aquélla, además de pastos de primavera, ofrecía el orujo — subproducto resultante de la molturación de la aceituna-, que revuelto con harina de cebada constituía el pienso del ganado porcino durante el verano; de ahí que con frecuencia esta especie ganadera pasase parte del estío en «los olivos».

En la Sierra Morena, las negativas condiciones agronómicas le preservaron de usos agrarios y de la ocupación humana. Su cobertera vegetal era muy densa y no conoció más alteraciones que las conocidas por el pastoreo de ganado cabrío, saca de leña y carboneo y la apertura de algunos oquedales destinados a la plantación de frutales que, al menos en ley, debían contar con la autorización previa del Ayuntamiento (eran tierras de propios). Estos oquedales se abrieron en los lugares más accesibles y en los parajes de mejor calidad agronómica. Sobre ellos se plantaron olivos y dieron lugar a enclaves de reducidas dimensiones que más adelante, cuando en virtud de la Ley de Roturaciones Arbitrarias de 1869, se les reconoció a los roturadores como propiedad privada, fueron el fundamento de un parcelario minifundista cuyos titulares — en buena medida los cabreros antes aludidos- en adelante estaban llamados a desempeñar una función importante en el océano de latifundios que los circundaría. Efectivamente, estos minifundistas y sus familiares fueron durante muchos años el principal contingente de mano de obra para la explotación de los grandes olivares de sierra y, aún hoy, sus descendientes perviven como regentes en tenencia indirecta de las grandes explotaciones olivareras (Valle, 1995: 242). Así los grandes propietarios lograban atar el campesino a la tierra, concediendo pequeños lotes de tierra y contratándole como aparceros en sus grandes fincas de olivar de sierra.

6 A. León, en su libro sobre el municipio del valle del Guadalquivir de Palma del Río, también señala que «por lo general casi todos los propietarios importantes tenían cortijos en la sierra y en la campiña.» (León, 1990: 77) 
Este tipo de explotaciones que contaban con fundos dispersos y complementarios agroecológicamente alcanzaron un grado de rentabilidad hasta entonces desconocido, el cual se vio incrementado por la posibilidad que ofrecía el ferrocarril de exportar el ganado para abastecimiento de los grandes centros urbanos y, en otro orden de cosas, por la abundancia de mano de obra, producto tanto de la proletarización del campesinado subsiguiente a la desamortización, como del alza de población que estaba generando la transición demográfica. Ambas circunstancias, concluye Valle, permitieron la contratación de pastores para las nuevas explotaciones ganaderas en unas condiciones muy ventajosas para los propietarios de los rebaños, cuales eran las resultantes de un sistema de remuneración semiservil a «hato y piara» (una aparcería ganadera) y no en metálico.

A la interdependencia Dehesa-Sierra Morena-Campiña se debe añadir también las montañas Béticas que jalonan por el Sur al Valle del Guadalquivir. El papel jugado por las montañas y altiplanicies Béticas se manifiesta, entre otras claves, por ser un espacio suministrador de mano de obra para las cosechas de los cultivos campiñeses y por la posesión de latifundios de los grandes propietarios tanto en la Campiña como en estas comarcas serranas, en un intento de controlar también la producción del olivar. En este aspecto, Ortega ofrece algunas aportaciones, señalando como los segadores de la Subbética bajaban a la Campiña con el sistema al tercio y a su vez los habitantes de la Campiña subían a la recogida de la aceituna (aunque menos porque la Subbética estaba muy poblada ${ }^{7}$ ) (Ortega, 1975: 147, vol. I). Este mismo autor, cuando explica la potencialidad económica de los grandes propietarios olivareros de la sierra Sur de Córdoba, aduce como argumento el que posean tierras también en la Campiña (Ortega, 1975: 117, vol. II):

«Las tierras cultivadas de los grandes propietarios presentan una marcada tendencia al monocultivo olivarero: sus propiedades constituyen verdaderas «plantaciones» en el sentido de que entran de lleno en el juego de una agricultura de mercado muy especializada. En general esto es posible por la capacidad de inversión de sus titulares, que les permite tener las tierras mecanizadas siempre que las condiciones del relieve lo permitan. Además, mucho de estos grandes propietarios son olivareros aquí en nuestra Comarca y labradores cerealistas, algodoneros, etc., en la Campiña, puesto que sus tierras no se reducen a las que nosotros contabilizamos.»

De esta manera, la producción de aceitunas y aceite, trigo, pastos, explotación silvícola, caza, lácteos, cerdo, caprino, ovino y vacuno podía estar en manos de un mismo propietario, combinándose en sus explotaciones tanto formas de trabajo asalariado (cosecha de trigo, de aceituna, de algodón) como precapitalistas (olivares a medias, «parcelistas» en riego, medianería en barbechos, aparcerías ganaderas de «hato y piara», trabajo gratuito en el «descuaje» para el adehesamiento del bosque mediterráneo o en la poda del mismo, etc.). Es la economía terrateniente sintetizada en un solo propietario, resultado de la combinación del sistema capitalista con el sistema de pago en trabajo (semiservil o precapitalista) que pervivió hasta los años sesenta del siglo XX.

7 Se trata de campesinos sin tierra y pequeños campesinos a los que F. Ortega denomina jornaleros y «jornaleros-propietarios». Es su estudio sobre las Subbéticas cordobesas éstos últimos son numerosísimos todavía a mediados del siglo XX y suponen el 88,63 por 100 de todos los propietarios: 71,36 por 100 los que poseen menos de una ha y 17,27 por 100 los que tienen entre 1 y 5 (Ortega, 1975: 118, vol. II). No hubo descampesinización total tampoco en las sierras Béticas. 


\section{Conclusiones}

Los distintos sistemas agrarios andaluces, producto de la diversidad ecológica de la región, tienen en común la presencia en todos ellos de la gran propiedad latifundista combinada con los campesinos pobres y los campesinos sin tierra. Hasta los años sesenta del siglo XX, la gran propiedad organizó los sistemas agrarios andaluces, desde el punto de vista de las relaciones de producción, mediante la combinación de contratos a jornal con regímenes de tenencia claramente precapitalistas (medianería, aparcería, trabajo gratuito, etc.). El resultado fue el escaso desarrollo de la capacidad productiva de la región, causa última de su histórico atraso. La crisis agropecuaria de los años sesenta (éxodo rural y posterior mecanización del campo andaluz) no determinó la desaparición de la gran propiedad latifundista, sino que ésta se adaptó a las nuevas circunstancias socio-económicas mediante su influencia en las instituciones del Estado: generación de leyes y políticas favorecedoras hacia la gran propiedad (Ley de Caza, Ley de Montes, subvenciones estatales y comunitarias) y control de la mano de obra jornalera (Empleo Comunitario y sistema P.E.R-Subsidio Agrario).

\section{Bibliografía}

CABANAS PAREJA, R. (1967): «Los Pedroches». Estudios Geográficos, nº 106-107, pp. 23-88 y 197-242.

CANO GARCÍA, G. (1975): La Comarca de Baza. C.S.I.C. Madrid, 523 pp.

CARRIÓN, P. (1932, ed. 1975): Los latifundios en España. Su importancia. Origen. Consecuencias y solución. Ariel. Barcelona, 489 pp.

CRUZ VILlaLÓN, J. (1980): Propiedad y uso de la tierra en la Baja Andalucía. Carmona, siglos XVIII-XX. M.A.P.A. Madrid, 360 pp.

CRUZ VILLALÓN, J.; OJEDA RIVERA, J. F.; ZOIDO NARANJO, F. (1980): «Explotación familiar y estrategias campesinas en los nuevos regadíos béticos». Agricultura y Sociedad, $\mathrm{n}^{\circ} 17$, pp. 11-67.

CUESTA AGUILAR, M. J. (2001): Dinámica erosiva en los paisajes de la cuenca del río Guadajoz (Córdoba y Jaén). Secretariado de Publicaciones de la Universidad de Córdoba, Córdoba, 226 pp.

DÍAZ DEL MORAL, J. (1995): Historia de las agitaciones campesinas andaluzas. Alianza Universidad. Madrid.

FERRER RODRÍGUEZ, A. (1982): Paisaje y propiedad en la tierra de Alhama (Granada, siglos XVIII-XX). Universidad de Granada. Granada, $591 \mathrm{pp}$.

LENIN, V. I. (1975): El desarrollo del capitalismo en Rusia. Obras Completas, Tomo III. AyusoAkal. Madrid, $670 \mathrm{pp}$.

LEÓN LILLO, A. (1990): Palma del Río. Diputación Provincial de Córdoba. Córdoba, 372 pp.

LÓPEZ JIMÉNEZ, R. (1972): «Aportaciones al estudio de las explotaciones de caza mayor de Sierra Morena Occidental». Archivos de zootecnia, nº 82, pp. 167-191.

LÓPEZ ONTIVEROS, A. (1974): Emigración, propiedad y paisaje agrario en la Campiña de Córdoba. Ariel. Barcelona, 607 pp.

LÓPEZ ONTIVEROS, A. (1981): «El desarrollo reciente de la caza en España», en Supervivencia de la montaña. Actas del Coloquio Hispano-Francés sobre las áreas de montaña. Madrid, MAPA, pp. 271-297.

LÓPEZ ONTIVEROS, A. (1986b): «Caza y actividad agraria en España y Andalucía: su evolución reciente». Agricultura y Sociedad, $\mathrm{n}^{\circ}$ 40, pp. 67-98.

LÓPEZ ONTIVEROS, A.; VALLE BUENESTADO, B. (1987): «Implicaciones agrarias del turismo cinegético español», en IV Coloquio Nacional de Geografía Agraria. Departamento de Geografía de la Universidad de La Laguna - A.G.E. La Laguna, pp. 85-94. 
MÁRQUEZ FERNÁNDEZ, D. (1977): La geoeconomía forestal de Huelva y el dilema de sus eucaliptales. Instituto de Desarrollo Regional - Universidad de Sevilla. Sevilla, 269 pp.

MARTÍNEZ ALIER, J. (1968): La estabilidad del latifundismo. Análisis de la interdependencia entre relaciones de producción y conciencia social en la agricultura latifundista de la Campiña de Córdoba. Ruedo Ibérico. Francia, 419 pp.

MATA OLMO, R. (1979): La gran propiedad en los Llanos de Antequera. Instituto Juan Sebastián Elcano - C.S.I.C. Madrid, 108 pp.

MATA OLMO, R. (1987): Pequeña y gran propiedad agraria en la depresión del Guadalquivir. M.A.P.A. Madrid, 2 vols, 334 y 447 pp.

MORÁN MARTÍN, R. (1996): «Benamejí», en Actas de las Primeras Jornadas de la Real Academia de Córdoba en Benamejí. Córdoba, pp. 279-290.

MULERO MENDIGORRI, A. (1991): «Turismo y caza en España. Estado de la cuestión». Agricultura y Sociedad, $\mathrm{n}^{\circ}$ 58, pp. 187-214.

MULERO MENDIGORRI, A. (1995): Espacios rurales de ocio. Significado general y análisis en la Sierra Morena Cordobesa. M.A.P.A. Madrid, 584 pp.

NAREDO, J. M.; RUIZ MAYA, L.; SUMPSI, J. Mª (1977): «La crisis de las aparcerías de secano en la posguerra». Agricultura y Sociedad, $\mathrm{n}^{\circ}$ 3, pp. 9-67.

OCAÑA OCAÑA, C. (1987): Latifundio, gran explotación y modernización agrícola. Una reflexión sobre Andalucía. Universidad de Málaga. Málaga, 91 pp.

ORTEGA ALBA, F. (1973): «Pervivencias de la enfiteusis en el Subbético de Córdoba». Estudios Geográficos, no 132-133, pp. 713-715.

ORTEGA ALBA, F. (1975): El Sur de Córdoba. Estudio de Geografía Agraria. 2 vols. Monte de Piedad y Caja de Ahorros de Córdoba. Córdoba, 186 y 258 pp.

PEÑA HURTADO, J. (1985): «El cazador español ante la presión del turismo cinegético», en Actas de las II Jornadas de turismo cinegético. Dirección General de Política Turística, Servicio de Actividades Turísticas. Madrid, pp. 33-36.

RIVERA MATEOS, M. (1992): Explotación agraria y ocupación del espacio productivo en Sierra Morena. Universidad de Córdoba. Córdoba, 134 pp.

ROUX, B. (1975): Crisis agraria en la Sierra Andaluza. Un estudio económico de las empresas ganaderas de la provincia de Huelva. Instituto de Desarrollo Regional - Universidad de Sevilla. Sevilla, 274 pp.

TORRES MÁRQUEZ, M. (2002): La zona regable del Guadalmellato (Córdoba).Su desarrollo reciente y situación actual. Tesis Doctoral (inédita). Departamento de Geografía. Universidad de Córdoba. Córdoba, 2 vols., 1149 pp.

VALLE BUENESTADO, B. (1977): «Los cotos de caza mayor en la provincia de Córdoba», en $M e$ dio Físico, Desarrollo Regional y Geografía, V Coloquio de Geografía. Universidad de Granada - A.G.E. Granada, pp. 589-595.

VALLE BUENESTADO, B. (1985): Geografía agraria de Los Pedroches. Excma. Diputación Provincial de Córdoba. Córdoba, 600 pp.

VALLE BUENESTADO, B. (1995): «Los paisajes agrarios del Norte de Córdoba: Sierra Morena y Los Pedroches», en Ponencias y excursiones del VII Coloquio de Geografía Rural: Propiedad, actividad agraria y medio ambiente en España y América Latina. Diputación Provincial de Córdoba - Universidad de Córdoba. Córdoba, pp. 235-260. 